\title{
Secured and efficient convergence of artificial intelligence and Internet of things
}

Published online: 7 August 2021

( ) Springer Science+Business Media, LLC, part of Springer Nature 2021

Multimedia Tools and Applications gratefully acknowledges the editorial work of the scholars listed below on the special issue entitled "Secured and Efficient Convergence of Artificial Intelligence and Internet of Things" (SI 1194).

Of 47 papers submitted to this issue, 11 were eventually accepted after a stringent peer review process.

\section{Corresponding Guest Editor}

Fazlullah Khan

Rozetta Institute, formerly CMCRC, Australia

Email: fazl.ullah@rozettainstitute.com; fazlullah.mcs@gmail.com

\section{Guest Editors}

\section{Lie-Liang Yang}

Southampton University, UK

Email: 1ly@ecs.soton.ac.uk

\section{Ateeq ur Rehman}

Abdul Wali Khan University Mardan, Pakistan

Email: ateeq@awkum.edu.pk

\section{Mian Ahmad Ja}

Northwestern Polytechnical University, China

Email: mianjan@nwpu.edu.cn

Publisher's Note Springer Nature remains neutral with regard to jurisdictional claims in published maps and institutional affiliations. 